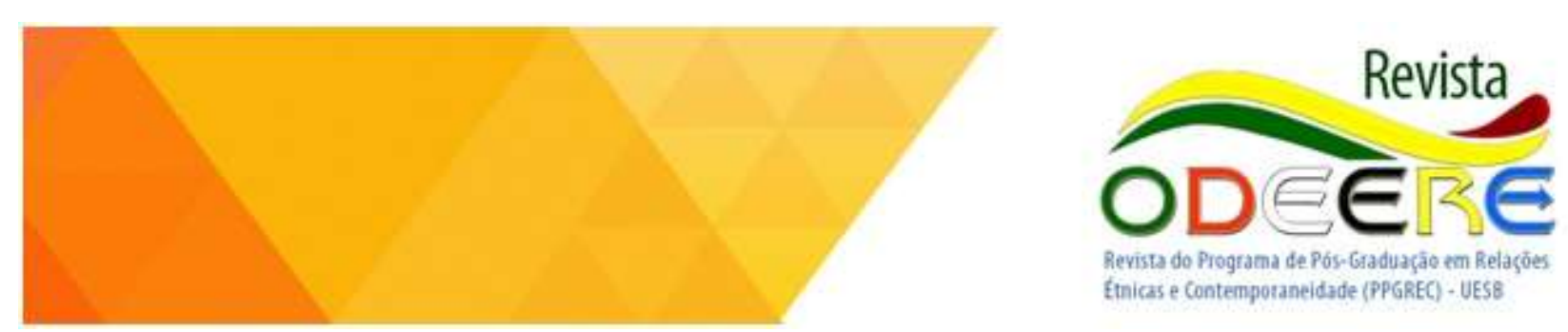

\title{
(DES)CONSTRUÇÃO DE SABERES AFRO
}

\section{(DE)CONSTRUCTION OF AFRO KNOWLEDGE}

\author{
Sávio Oliveira da Silva Santos \\ (iD) http://orcid.org/0000-0003-1036-9824 \\ Universidade do Estado da Bahia \\ savio123oliver@gmail.com
}

\section{DOI: 10.22481/odeere.v5i9.6347}

RESUMO: $O$ referente trabalho tem por objetivo descrever parte das experiências obtidas mediante a participação na extensão em "Educação e Cultura Afro" desenvolvida pelo Órgão de Educação e Relações Étnicas - ODEERE. Na oportunidade, refletimos sobre as discussões obtidas nos dez módulos do curso e como essas pautas influíram diretamente nas concepções pressupostas acera da cultura afro. Em vista de se perceber o legado africano assumindo metodologias de resistência na contemporaneidade, a formação docente e discente deve procurar reaver e fortalecer de forma diversificada sua identidade e seu território para combater a discriminação racial. Dessa forma, o presente trabalho discorre sobre a importância do curso para alunos, professores e a comunidade em busca de melhor formação e rompimento do status quo étnico. Entretanto, aprendendo a respeitar e valorizar a cultura, o legado africano, a educação étnico-racial, por meio de práxis realmente efetivas em seus respectivos territórios de identidade.

Palavras-chave: Educação; Cultura; Afro; Saberes.

ABSTRACT: The purpose of this work is to describe part of the experiences obtained by participating in the extension on "Afro Education and Culture" developed by the Education and Ethnic Relations Agency ODEERE. On the occasion, we reflected on the discussions obtained in the ten modules of the course and how these guidelines directly influenced the presupposed conceptions of Afro culture. In order to perceive the African legacy assuming resistance methodologies in contemporary times, teacher and student training must seek to recover and strengthen in a diverse way their identity and their territory to combat racial discrimination. Thus, the present work discusses the importance of the course for students, teachers and the community in search of better training and disruption of the ethnic status quo. However, learning to respect and value culture, the African legacy, ethnic-racial education, through truly effective praxis in their respective territories of identity.

Keywords: Education; Culture; Afro; Knowledge. 


\section{INTRODUÇÃO}

A ruptura é uma ação muitas vezes necessária para sedimentar algo maior ou inovador, favorecendo nossas visões, rompendo padrões estabelecidos, inclusive, com tradicionais. O Órgão de Educação e Relações Étnicas - ODEERE, em uma concepção particular, representa rupturas, tanto quanto o contra cânone é: a ida contrária às concepções estabelecidas por quem fundou os grandes centros de estudos e a ciência; recorte pertinente dentro de espaços totalmente verticalizados, elitizados e branqueados. A visão obtida do ODEERE é de um grupo de pessoas engajadas com as questões e movimentos sociais que perceberam a necessidade de "ativizar" as teorias apenas discutidas na universidade.

Dessa forma, passando a se estabelecer de forma párea à universidade, mas ao mesmo tempo desolada de suas rédeas inclusas no seu discurso utópico, mas dúbio. O trabalho com a comunidade, o zelar pelo espaço e o respeito pela cultura e educação afro-brasileira produziram resultados significantes na educação, na comunidade e nos estudantes que a ela ingressaram. Ocasionalmente, sua valorização se tornou regional.

Em 2019 ingressamos no curso de Educação e cultura afro, nele esperava-se discutir e aprender acerca de melhores ações, metodologias e praticas pedagógicas para trabalhar a 10.639/2003, mas essas expectativas foram superadas. O curso disponibilizou bem mais do que o esperado e tornou-se possível trabalhar diretamente com a cultura africana de forma prática, compromissada e intensa. Dessa forma, rompendo preceitos, porque não dizer: preconceitos, aprendendo sobre as religiões de matriz africanas no seu papel social, como perpetuadoras da cultura e do legado africano.

Foram 10 módulos de bastante aprendizado e intentando melhor exposição da experiência obtida, a posteriori, seguem breves relatos de cada módulo, fotos que elucidam a carga de conhecimento imensurável proporcionada pelo curso, o qual nos deixou contribuições para a formação pessoal, cidadã e profissional.

\section{DESCRIÇÃO/RELATO DOS MÓDULOS}

Módulo I: O primeiro encontro para o curso de extensão foi desenvolvido por meio da participação dual no V Seminário de Pós-graduação em Relações Étnicas 
e Contemporaneidade, e no XV Encontro de Combate à Discriminação Étnica. O evento continha o tema: "As pesquisas em relações étnicas: discriminações e proposições" e ocorreu nos dias 22-24 de março de 2019.

Dentro do evento os participantes receberam as boas vindas $e$ as orientações necessárias sobre o programa, estruturas do ODEERE, cronograma e normas da extensão. Nesse primeiro encontro foi possível perceber um maior engajamento e compromisso das pessoas da comunidade, estudantes da especialização, mestrado e atuais formandos do módulo anterior do curso de extensão ocorrido em 2018 nas pesquisas com enfoque na área de etnicidade. Assim, corroborando no interesse maior para as atividades acadêmicas e individuais em prol dos estudos afrocentrados.

Uma das grandes contribuições do encontro foi a apresentação dos programas de especialização e mestrado fomentados pela Universidade Estadual do Sudoeste da Bahia - UESB em parceria com o ODEERE. Como estudante de outra instituição de nível superior, da Universidade do Estado da Bahia - UNEB, que já pesquisava no referente campo de pesquisa e objetivava conhecer as estruturas e programas, o evento dual se tornou egrégio ao hibridar dois interesses de forma única.

As palestras e discussões foram autênticas e demonstravam realmente não apenas domínio do tema, mas os pesquisadores, em lugar de fala, obtiveram êxito na apresentação de suas pesquisas. O primeiro módulo findou-se alcançando seu objetivo: saudar e incentivar os novos ingressantes do curso de extensão, turma 2019.

Módulo II: Ocorrido nos dias 13 e 14 de abril com o tema "Métodos e Técnicas para o ensino de linguagens visuais e culturas", o segundo encontro do curso de extensão uniu no auditório Waly Salomão os estudantes de todos os cursos de extensão do ODEERE. O módulo foi lecionado pelos professores: Dr. Edson Dias Ferreira e o Prof. Ms. Antônio Argolo Silva Neto. O encontro se deu entre duas etapas, no primeiro dia (sábado) houve a apresentação dos professores, leitura de informes importantes para o andamento do curso e exposição teórica sobre a metodologia dos estudos visuais, dentre eles: enquadramentos de fotos, vídeos, conteúdos e perspectivas do bom alcance visual para explorar um tema dentro 
dos estudos étnicos mediante ao ajuste correto da ferramenta tecnológica, assim, alcançando bons resultados por meio da metodologia adequada a ser aplicada à pesquisa.

Na parte da tarde do dia 13 (sábado) e do dia 14 (domingo) pela manhã, os participantes foram direcionados às estruturas do ODEERE, onde aconteceu grande parte das atividades. Divididos em grupos mesclados, os cursistas foram orientados a desenvolverem um vídeo sobre um dos enquadramentos de câmera apresentados na exposição teórica a partir de um tema consensual do grupo.

Como integrante do grupo 7, desenvolvemos uma pesquisa de campo utilizando de entrevistas com as mulheres negras feirantes do bairro do Jequiezinho. Para tanto, incluíram-se filmagens e recortes intertextuais - músicas, fotos e vídeos; bem como uso dos recursos visuais do museu do ODEERE, entre outros. Com a coleta dos dados, objetivou-se analisar as faces das mulheres negras nas concepções religiosas nas religiões de matriz africanas correlacionadas com seu papel social enquanto trabalhadora.

O vídeo obteve uma boa qualidade e foi exposto pelo grupo na tarde do domingo - dia 14, os participantes se apresentavam e o líder do grupo, ao final da exposição do vídeo explanava suscintamente sobre como foi desenvolvido o vídeo, a forma como a metodologia possibilitou alcançar o objetivo e explorar o tema. Ao final das exposições, o professor Edson reitera as análises, parabeniza os grupos e encerra o módulo Il.

Módulo III: Realizado nos dias 18 e 19 de maio de 2019, o terceiro módulo do curso de "Didática nas relações étnicas", fomentado pelo ODEERE, objetivou explorar as diversas formas de se entender o processo de construção do conhecimento. O módulo, mediante a leitura do segundo capítulo do livro "ODEERE: formação docente, linguagens visuais e legado africano no sudoeste baiano", sugestionado pela ministrante, possibilitou-nos entender sucintamente sobre a estruturação da instituição e como é importante valorizar as falas dos mais velhos por meio da oralidade como porta-vozes do legado africano.

Torna-se importante salientar que no início do curso, os participantes do curso de extensão em Educação e Cultura Afro-Brasileiras, tiveram a honra de ouvir a Mãe Marinalva relatando um pouco sobre sua vida, história e desafios de ser uma 
mulher negra, periférica e adepta do candomblé. Como nossa griô, ela ajudou a sanar algumas dúvidas importantes sobre a religião, conceituando e discutindo as relações raciais com a religiosa.

Isto posto, mediante a leitura de outro texto sobre Didática, entendemos que o aluno ou qualquer pessoa necessita de exemplificações e induções sobre diversos assuntos pautados. Quando tratamos das questões raciais no âmbito educacional, é necessário correlacionar o que é falado com o seu conhecimento prévio. A dedução correta das informações lançadas a luz do que é dito, é a meta de todo professor, palestrante, formador de opinião. Dessa forma, utilizar da didática não é apenas dispor de uma simbologia do conhecimento, mas uma ferramenta de exploração, construção e reestruturação dos ideais já contidos pelo interlocutor. O curso de encerra mediante uma breve e contundente fala da professora Marise Santana sobre a precisão do ODEERE, e da Mãe Marialva reafirmando a inevitalidade do nosso dever de resistência, racial, social e religiosa.

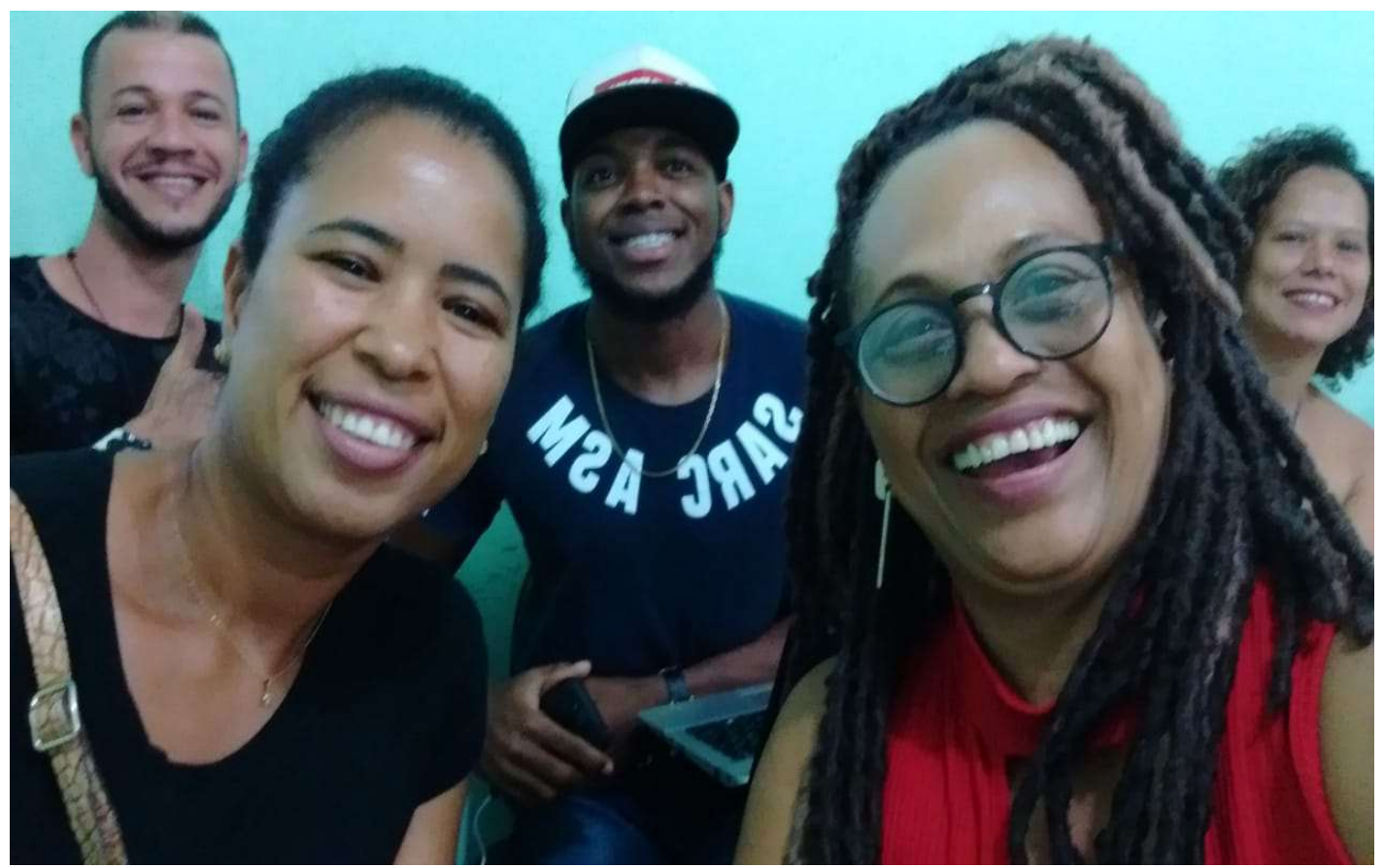

Figura 1: Foto dos cursistas Paulo, Geovana, Tereza, Lusineide e o Autor (centro) no módulo III. Fonte: Arquivo pessoal do autor.

Módulo IV: O quarto módulo do curso Educação e Cultura Afro-brasileira, ocorrido nos dias 15 e 16 de junho de 2019, se deu de forma única e especial ao tratar da Antropologia das questões Afro-brasileiras. O curso intitulado "Cultura" lecionado pelo professor Natalino e pela Mestranda Dócio, fomentou espaço de 
debate sobre o conceito de cultura: sua diversidade e preceitos que, a cada um, rege. A priori, trabalhamos o conceito pessoal de cultura em que, pessoalmente, descrevemos como: práticas demandadas a partir do espaço habitual de alguém. Ela pode ser apropriada ou herdada a partir do que reconhecemos como necessário, principalmente no teor subjetivo e transcendente do sujeito. A posteriori, foi sugerido também que conceituássemos, a partir do nosso conhecimento prévio, a diferença entre cultura brasileira e cultura africana, assim, sucintamente, apontamos que: cultura brasileira é pluricultural, pois foi formada a partir de diversas oscilações imigratórias na sua história. A cultura africana, mesmo passando por muitas demandas históricas, ela consegue e conseguiu se estruturar monoculturamente, isto é, ela não dispõe apenas de uma cultura, porém a sua nativa foi mantida.

Como esperado, ademais, o curso conseguiu expandir nossa compreensão, por meio do texto de Roque Laraia (1932-) intitulado "Cultura: um conceito antropológico", do que antes acreditávamos ser a reposta do conceito de cultura e suas diferenças, e, assim, pudemos fazer um comparativo do nosso entendimento prévio com os apontamentos teóricos do autor. No ensejo, oportunizamos os debates para compreender como o determinismo biológico e geográfico eram utilizados como métodos de classificação dos homens na questão racial e regional.

O referente módulo deu-se de forma criativa, a práxis entre a correlação teórica de cultura e a prática, como exploração das diversas formas e afirmativas de identidade no sudoeste baiano abrilhantaram as apresentações como resultados das pesquisas hibridadas historicamente no Sudoeste baiano. O grupo 1, do qual fizeram parte: Sávio, Paulo, Leila, Lusineide e Silvana, ficou com o tema "Africanos e negros no sudoeste baiano: histórias, influências e culturas". Na oportunidade, procuramos, já que cada um pertencia a uma cidade do Território Médio Rio das Contas, identificar algumas histórias sobre os primeiros habitantes das cidades de Ipiaú, Maracás, Ibirataia, Jequié e Itiruçu.

Por meio dos contos populares identificamos o primeiro prefeito de Ibirataia, que era um homem negro, o Dr. Aristóteles; discutimos a problemática das terras que foram dadas aos italianos que chegaram fugidos da II Guerra Mundial à cidade de Itiruçu enquanto a população negra que ali habitava não recebeu nenhuma terra ou contribuição do governo, além disso, como a sociedade no 
município e no mundo ainda reflete o resultado dessa atitude governamental na vida dos descendentes de cada raça, a negra, quilombola e dos italianos. Além disso, o grupo conseguiu apontar algumas manifestações culturais dessas cidades e perceber as influências africanas no sincretismo religioso do candomblé e do catolicismo; os grupos de capoeira e suas diversas formas de apresentações em cada cidade; a umbanda e suas personalidades mais influentes em cada cidade; o bumba meu boi; o terno de reis, entre outras manifestações que exploram a cultura africana hibridada com tantas outras influências religiosas e culturais.

Como embasamento das afirmativas do grupo, utilizamos do livro "ODEERE: formação docente, linguagens visuais e legado africano no sudoeste baiano" para analisar a presença dessas culturas como herança dos povos negros africanos diásporos em direção ao sudoeste baiano. Assim, pelos escritos do professor, escritor e antropólogo Washington Santos, conseguimos perceber a presença antológica das práticas dos Bantos na Bahia, necessariamente, no sudoeste baiano. Sobre a presença de africanos no sudoeste baiano, o antropólogo aponta que:

No estágio atual e nossas pesquisas é difícil responder a essa pergunta. A falta de uma pesquisa sistemática sobre o tráfico interno para o sudoeste baiano nos impede de fazer afirmativas mais conclusivas, mas nossas pesquisas demonstram uma predominância de escravos bantos se deslocando para o sertão baiano. Outro fator que nos ajuda a solidificar essa hipótese são as práticas culturais e religiosas da região ligadas ao terno de reis, a umbanda, ao samba de umbigada etc., o que nos remete a tradições também banto. A própria maleabilidade cultural desses africanos em suas relações com indígenas e europeus e o caráter igualmente maleável do que chamaremos de cultura popular sertaneja, são fatores que só fortalecem o que por hora é só uma hipótese.

Além disso, o professor Washington Santos acalenta a discussão baseando o que seria o Banto e correlacionando com as práticas do sudoeste baiano, frente às pesquisas desenvolvidas por outros historiadores.

Segundo Marina e Mello e Sousa (1986, p. 139), banto é uma '[...] designação genérica, criada a partir de afinidades linguísticas, que remetem a uma remota origem comum e a um movimento de lenta ocupação de grande parte do território africano'. Viviam na África CentroOcidental, eram compostos por uma enorme variedade de povos organizados em aldeias, confederações e reinos, cujos povos possuíam uma unidade linguística que permitiu aos estudiosos considera-los de uma mesma

1 SANTANA, Marise de, ODEERE: formação docente, linguagens visuais e legado africano no sudoeste baiano / Marise Santana... [et al.]. - Vitória da Conquista: Edições UESB, 2014. 
família. (Idem)

Assim, o curso se encerra com as outras apresentações que nos atentam para entender as influências africanas na nossa região, na nossa cidade e na nossa vida por meio das nossas práticas e culturas. Sobre o conceito de cultura, percebemos que não existe um conceito concreto, o qual se possa afirmar como verdade, mas é possivel de destrinchá-lo e identificá-lo a partir das nossas vivências, histórias e intermédios a nós chegados. Assim, a ideia de cultura, sucintamente, estabeleceu-se como forma de solidificação daquilo que praticamos e acreditamos como herança de povos ou apropriação do que entendemos como importante na nossa vida.

Módulo v: O módulo cinco, ocorrido nos dias 13 e 14 de junho, lecionado pela professora Dra. Cristiane Batista da Silva Santos, canalizou uma série de conhecimentos prévios sobre o continente africano. Os estudos de mapas, distinguindo alguns países, regiões e permeando além da crua geografia, entretanto penetrando nas questões culturais frente das migrações e emigrações do período escravocrata recebidas, pudemos perceber como é possível entender seus contextos no período hodierno a partir dessas nuanças históricas.

A quebra de preceitos como: África só tem negros; África só tem fome e miséria; os africanos já se escravizavam etc., foram desmitificados, empenhando nos cursistas o papel do professor na propagação dessas noções básicas. Essa posteriori aplicação, letramento geográfico, histórico também foi trabalhado em sala, onde os alunos criaram um plano de aula para quebrar as ideias refutadas no curso e que são provenientes dos saberes equívocados sobre o continente africano. Podemos apontar que essas práxis -- entre aula teórica e atividade profissional -- fomentou de forma potente o interesse na permanência no curso, no melhor desenvolvimento profissional como professor de língua portuguesa e na importância de se trabalhar as questões étnico-raciais de forma consistente na escola. Ocasionalmente, delas brotarão a pertença, as ideias de reconhecimento cultural, racial e identitário dos alunos.

A professora do curso sugeriu a elaboração de um texto individual intitulado: "Quando eu me tornei negro", o texto foi norteador para entender a nossa posição 
social na atualidade, trabalhando com as concepções dos negros pós-modernos - talvez ainda modernos -, sobre o nosso lugar na sociedade e enquanto herdeiros de uma história de luta e resistência. Outro ponto importante a ser notado no curso de História da África foi o uso de diferentes textos, necessariamente didáticos, onde notamos como existe um leque de informações sobre a África, sobre os reis e rainhas, pesquisadores, matemáticos, artesãos que não são relembrados e passam despercebidos nos nossos estudos tanto acadêmicos quanto curriculares. O texto "As Marias" que questiona o sistema sobre o lugar das mulheres negras como guardiãs do legado africano, junto com a culinária e as religiões de matriz africana, reverberando sobre as netas dessas mulheres; todas as consequências que sofremos desde a infância nos diferentes espaços escolares: formais não formais e informais, e a perpetuação de atitudes embranquecidas, em busca de um padrão de conduta que corroborasse com a sociedade racial em distopia.

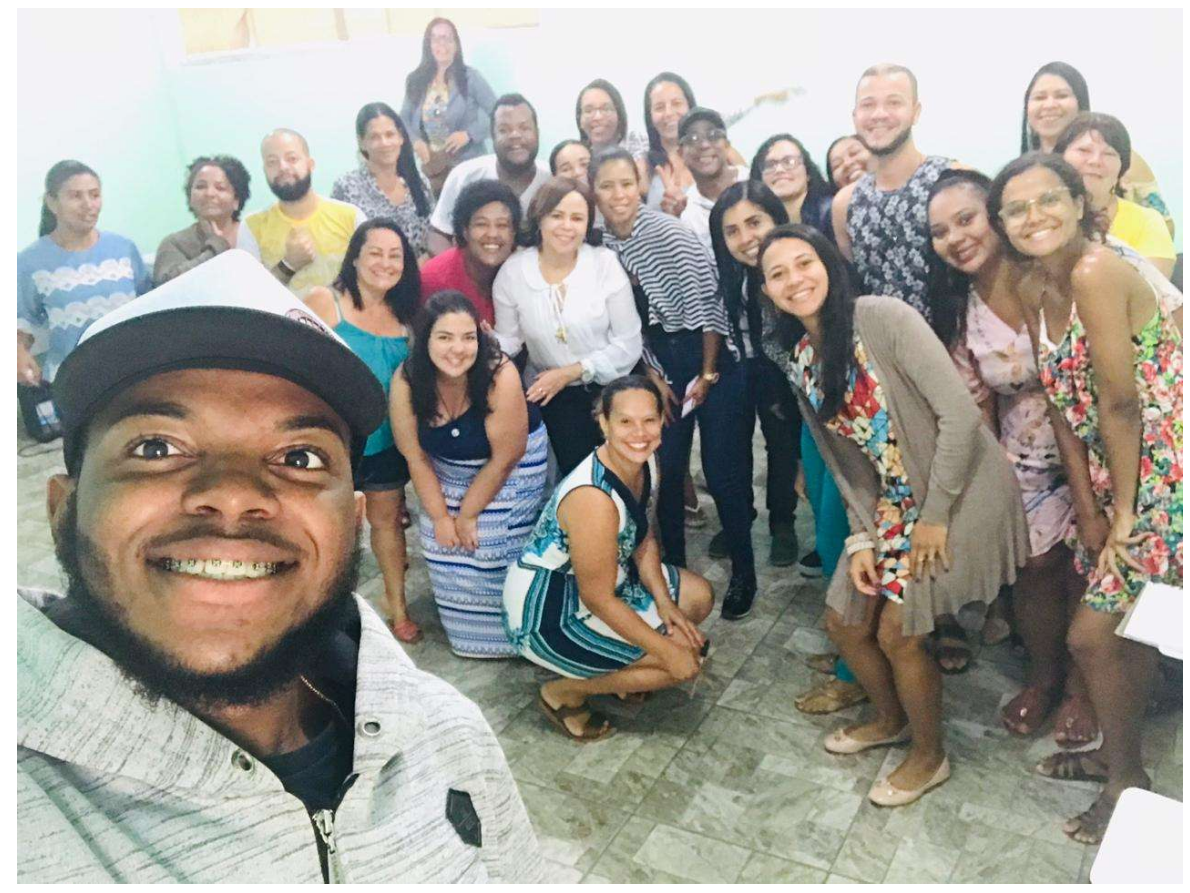

Figura 2: Foto dos cursistas com a professora Cristiane. Fonte: Arquivo pessoal do autor.

Por fim, contemplamos cinco vídeos de mulheres negras em diferentes locais da África, nos ambientes educacionais, no trabalho e na cultura. Depois, lemos em dupla contos sobre mulheres africanas e tecemos comentários enriquecedores correlacionando vídeos e contos, dessa forma, finalizando o curso com êxito, reflexões contundentes, inspiração e atividades escolares para aplicar em sala. 
Módulo VI. Esse módulo do curso de (educação e cultura afro) intitulado: "Educação simbólica" ocorrido nos dias 17 e 18 de agosto reverberou sobre noções de semiótica e da tradução dos símbolos linguísticos a partir de um corpus construídos ou escolhidos para dialogar com suas ideologias e cultura(s).

Nesse aspecto, tratou-se de conceituar algumas terminologias utilizadas no ambiente educacional e trabalhar formas de se tratar as competências e habilidades que tendessem para o diálogo entre simbologias culturais e saberes de cunho educativo. Assim, esse módulo possibilitou depreender a construção de novos conhecimentos mediados por troca de experiências, onde essa mediação se dá pela necessidade da preparação e competências dos respectivos currículos.

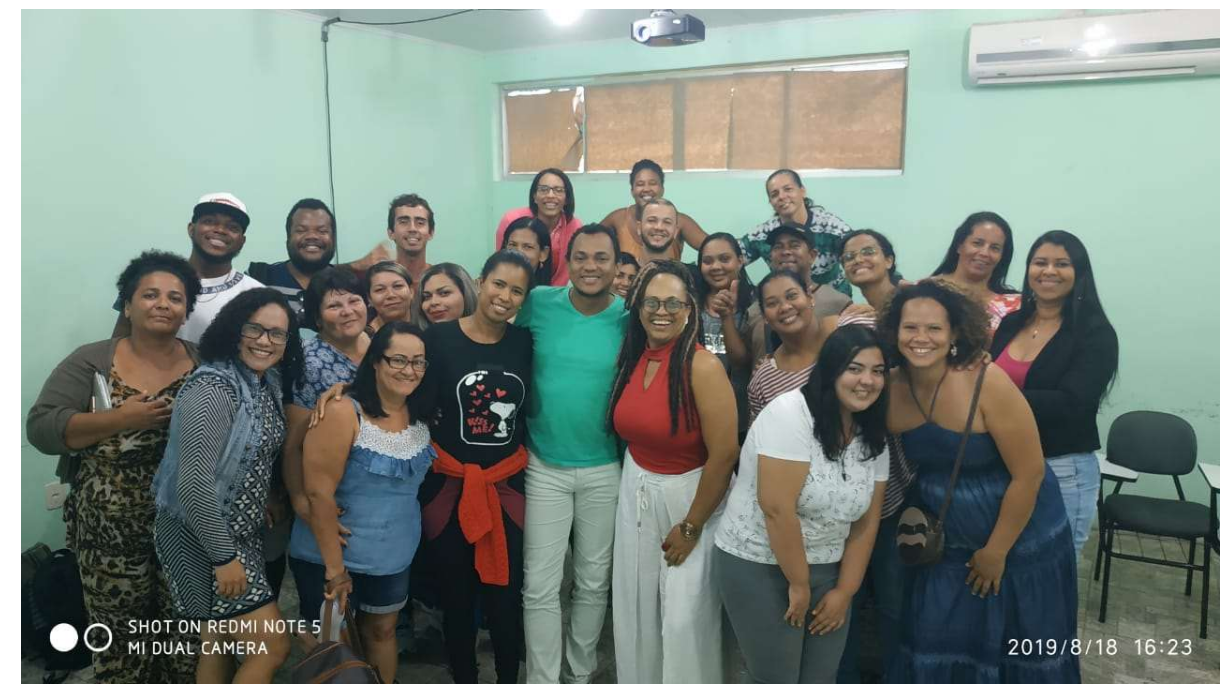

Figura 3: Foto da turma de "Educação e cultura afro" com o professor Eudes Batista. Fonte: Arquivo pessoal do autor.

A educação simbólica se estabeleceu como: todas as formas de representação de identidades, rituais, folclores e culturas que se interpela no ambiente educacional, seja ele, formal, não formal ou informal. Mas, nesse processo de representação, o que não se faz, a omissão de culturas, gestos, símbolos e ícones, também extrairá um significado. Isto é, ainda que paradoxal, a caracterização daquilo que não se expressa, há no seu sentido -- histórico - a construção de ideais que fizeram omitir tais manifestações, e, a partir disso fazê-las serem estudadas e tratadas nos ambientes escolares.

Outro ponto importante sobre os fundamentos da educação simbólica é que para seu desenvolvimento existe a necessidade de se abrir às novas perspectivas, leia-se: diversidade. Não pode existir um recorte educacional visando representar subjetividades, onde se impetra a cultura e a identidade, sem antes um processo 
de desconstrução ou maniqueísmo cultural, religioso ou político. O respeito aos símbolos páreos deve se estabelecer como pré-requisito na tentativa de educação por meio das simbologias.

Embora as rupturas culturais, os hibridismos, os sincretismos e, dessa forma, o surgimento de novos mitos e ritos tenham criado uma variedade de comunidades de adeptos e cada uma dela busquem suas representações, a história ainda visualiza tais sujeitos com base nas suas etnicidades, raças, ancestralidades e linguagens. Fato que favorece maiores representações, pois contempla um macro de identidades compostas nos sujeitos, mas, em contrapartida, surgem novas tentativas de representações simbólicas de identidades e culturas ocultas que vão emergir a partir da percepção do momento histórico e político.

Assim, a escola, como lugar de fomento às novas representações e que tenta construir diálogos dos saberes curriculares com os saberes prévios e culturais, deve-se reconhecer alguns signos linguísticos e culturais como ferramentas à quebra de hierarquias simbólicas e permanecer na busca pelo diálogo subjetivo e escolar. Ocasionalmente, possibilitando ao aluno mais interesse, mais orgulho identitário e novas formas de aprendizado a partir de seus saberes já construídos, seja na escola, em casa e/ou em suas demais comunidades de inserção.

Módulo VII: O módulo intitulado: "Antropologia das populações afro II", ocorrido nos dias 21 a 27 de setembro fora lecionado de forma totalmente prática. $\mathrm{Na}$ oportunidade, versou-se inicialmente com a professora Dra. Marise Santana sobre a questão do sincretismo religioso, a historicidade, mitos e rituais sobrepostos especificamente aos santos Cosme e Damião e suas simbologias e representações dentro das religiões de matriz africana.

A posteriori, começamos a atuar na organização do material alimentício que serviria no preparo para o banquete do tão famoso "Caruru do ODEERE", evento bastante conhecido pela comunidade do bairro "Pau de Ferro", por pessoas de outros bairros e pela comunidade acadêmica da UESB. O evento recebe a comunidade para o Caruru de Cosme e Damião, entrega brinquedos às crianças, além de servir a comunidade prestigiante.

A aula se estabeleceu no cerna do conhecimento prático-cultural, ou seja, a prática de cada ação, seja no âmbito da alimentação, ornamentação e/ou 
observação da cerimônia, cada coisa contendo sua singularidade e ali, ensinamentos a serem retirados para melhor compreender mais um fator da cultura afro brasileira.

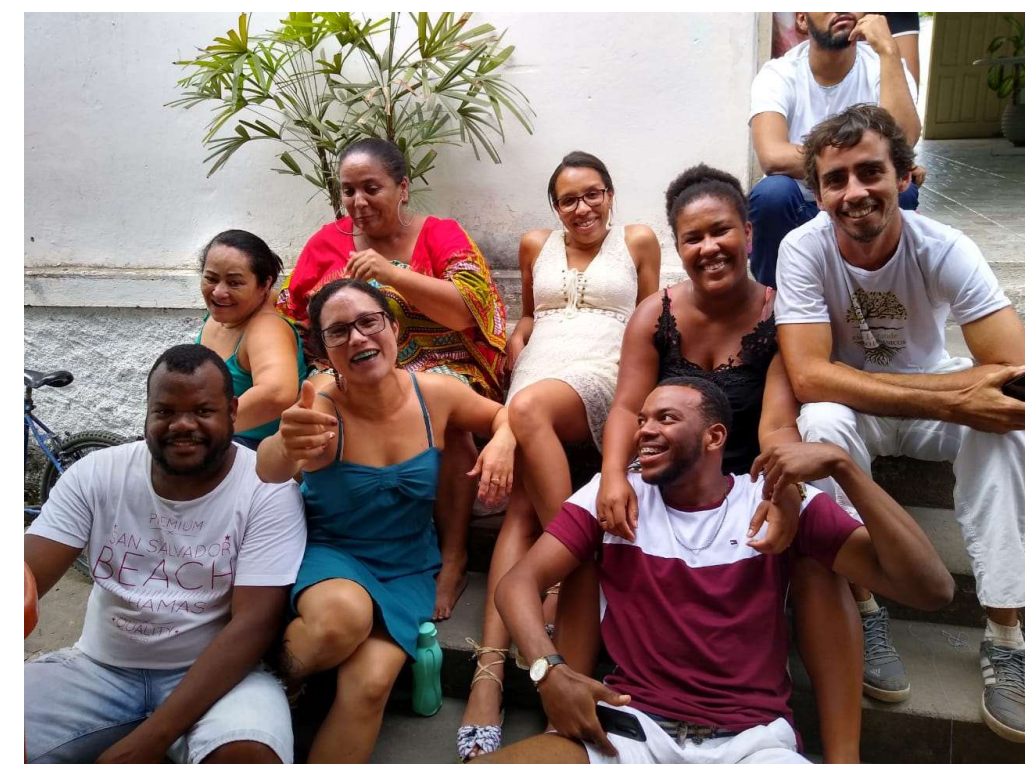

Figura 4: Foto dos cursistas Sávio, Silvana, Carla, Michele, Junior, Bela, Matheus e Leda, no Caruru do ODEERE (setembro/2019). Fonte: Arquivo pessoal do autor.

Por fim, o módulo se encerrou de forma festiva, saborosa e organizada, deixando visível que o estudo da cultura se dá não só pela presença, entrelaço e observação, mas também participação. Onde as comunidades de falas, de território, de raças e etnias não devem servir como nossos objetos de nossos estudos educacionais e culturais, mas como sujeitos e cidadãos ativos dos quais devemos propor formas contundentes de retorno/devolução gradativa e agradável como símbolos de toda proporção, talvez inconscientemente, fomentada.

Módulo VIII: O curso do módulo 8, intitulado: "Diversidade linguística dos grupos étnicos africanos" ocorrido nos dias 19 e 20 de outubro reverberou acerca das palavras em Banto ou lorubá descritas, utilizadas e conceituadas durante o Caruru do ODERRE, corrido há um mês antes. O curso lecionado por professoras do mestrado da referente instituição se comprometeu a instrumentalizar a percepção dos cursistas às palavras e falares africanos que são oriundos dos ancestrais africanos e povos tradicionais, bem como: quilombolas, povos originários e ciganos.

Entender como essas palavras se entrelaçaram com o português e o 
processo sofrido para que as línguas Banto e lorubá se adaptassem à língua portuguesa, sua variedade linguística e hibridismos que ocasionaram nas suas adequações semânticas, fonéticas, fonológicas, lexicais, sintáticas e prosódicas.

Após a divisão dos grupos para pesquisa de palavras solicitada pela docente, nos reunimos encarregados como segundo grupo de apresentação, e pesquisamos palavras de origem africana na música "Baiana", do rapper Emicida. Na oportunidade criamos um glossário das palavras contidas na música. Após ouvir e ler a música, discutimos a etimologia dessas palavras e a representação delas na lírica do artista como forma de representação de uma resistência e pertença. Ocasionalmente, foi possível perceber que as palavras ali estavam embutidas davam legalidade à originalidade do objetivo da música: referenciar a mulher baiana com a mulher africana em diáspora através do sincretismo, da pertença e dos traços.

As palavras de origem africana trazem consigo representações que muitas vezes são compreendidas equivocadamente por causa tanto do preconceito racial, quanto linguístico. Entender tais variações e suas veementes etimologias e perceber quão relevante é compreender a língua(gem) de um povo, raça antes ou durante o estudo da cultura afro-brasileira. Por fim, os outros grupos fizeram suas apresentações e o curso se encerrou com as mestrandas explicando seus respectivos projetos de pesquisa e dando os agradecimentos.

Módulo IX: Esse penúltimo módulo é um dos mais intensos e diversificados, sendo a XV Semana de Educação da Pertença Afro-Brasileira que engloba outros quatro eventos no seu decorrer. Na semana da pertença podemos vislumbrar de forma mais artística e diversificada o englobo dos outros módulos por meio de palestras engajadas, minicursos com temáticas pertinentes e apresentações de ótimos trabalhos de pesquisa. Diante disso, nós do curso de educação e cultura afro pudemos participar juntos do mesmo minicurso, o de libras. No ensejo, aprendemos alguns sinais de representações dos orixás pela língua brasileira de sinais, dessa forma, debatíamos também acerca da importância da LIBRAS e sua participação na lei 10.639, a qual visa garantir a educação afro brasileira nas escolas.

Outro fato importante foi poder ver algumas apresentações de trabalhos e 
contemplar os diversos vieses que a identidade negra pode tomar na academia. $\mathrm{Na}$ área da educação, por exemplo, ela é explorada e estudada em diversos cursos de licenciatura, sempre gerando novos questionamentos e produzindo resultados relevantes na academia, corroborando na formação dessas pessoas e acrescendo novas visões acerca da percepção do afro-brasileiro na comunidade.

Ademais, outro fator indispensável de menção, é o fato da comunidade se fazer presente no evento. É sabido que existe um certo distanciamento entre universidade e comunidade, contudo, a questão racial precisa dialogar diretamente com a comunidade externa, sendo ela seu objeto de estudo. Nesse sentido, a semana da pertença se mostrou um espaço de discussão direta, onde as pessoas adeptas das religiões de matriz africanas se sentiam confortáveis em estar em espaços por muitas vezes negados e reprodutoras de segregação, do racismo, do preconceito e da intolerância. Contemplar também o público secundarista, isto é, alunos do ensino médio, nos espaços da universidade não apenas como ouvintes, mas também como protagonistas, apresentando em dança, em jogral e em diversas outras formas o trabalho desenvolvido em suas escolas na cidade de Jequié, trouxe a luz a necessidade do engajamento do professor. Isso demonstra uma responsabilidade pela causa e desperta nos graduandos e graduados ali presentes uma sensibilidade e responsabilidade maior para com a sua respectiva área, com a lei 10.639/03 e com a educação.

Módulo X: O último e mais esperado dos módulos, o da viagem de campo. Ocorrida entre os dias 04 a 09 de dezembro, a viagem, ou melhor, a pesquisa de campo permeou entre as cidades de Cachoeira, Salvador e Candeias, necessariamente. Em vista de podermos estabelecer relação direta com os aprendizados no curso, desde o local de alojamento, o terreiro, até o museu etnológico e afro-brasileiro. Muitas dúvidas contidas foram respondidas no decorrer da pesquisa e pudemos desconstruir muitos saberes prévios e até o próprio senso comum acerca da cultura afro. 


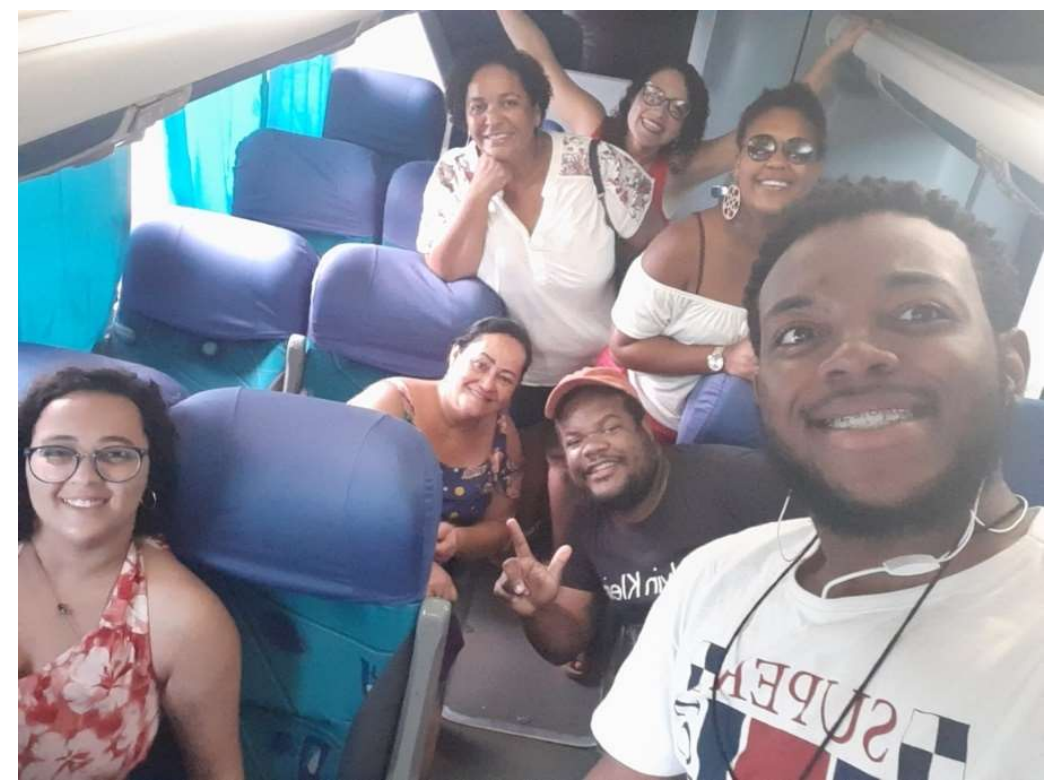

Figura 5: Foto dos cursistas: Sávio, Laura, Junior, Isabela, Silvana, Carla e Michele, no ônibus durante a viagem do grupo de pesquisa. Fonte: Arquivo pessoal do autor.

Na oportunidade, ouvimos sobre a função social do terreiro, principalmente no terreiro "Filho da Gomeia" onde eles produzem tecido, nos seus espaços ocorrem aulas de capoeira, é aberto ao turismo comunitário e contém uma ótima biblioteca aberta à comunidade. Fatos que vão em contrapartida à imagem tida sobre esses espaços que sempre foram vítimas de ataques de diversas formas devido a intolerância religiosa.

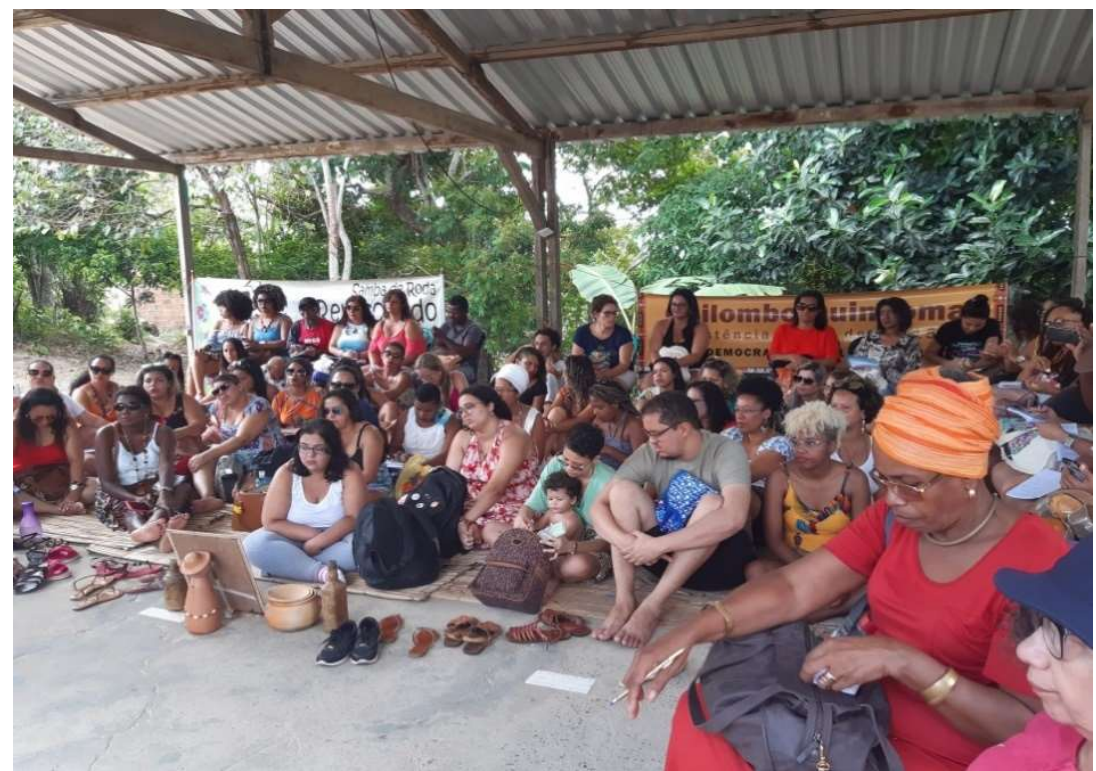

Figura 6: Foto dos cursistas e professores do grupo de pesquisa durante parada no Quilombo de Quingoma (Lauro de Freitas, 2019). Fonte: Arquivo pessoal do autor. 


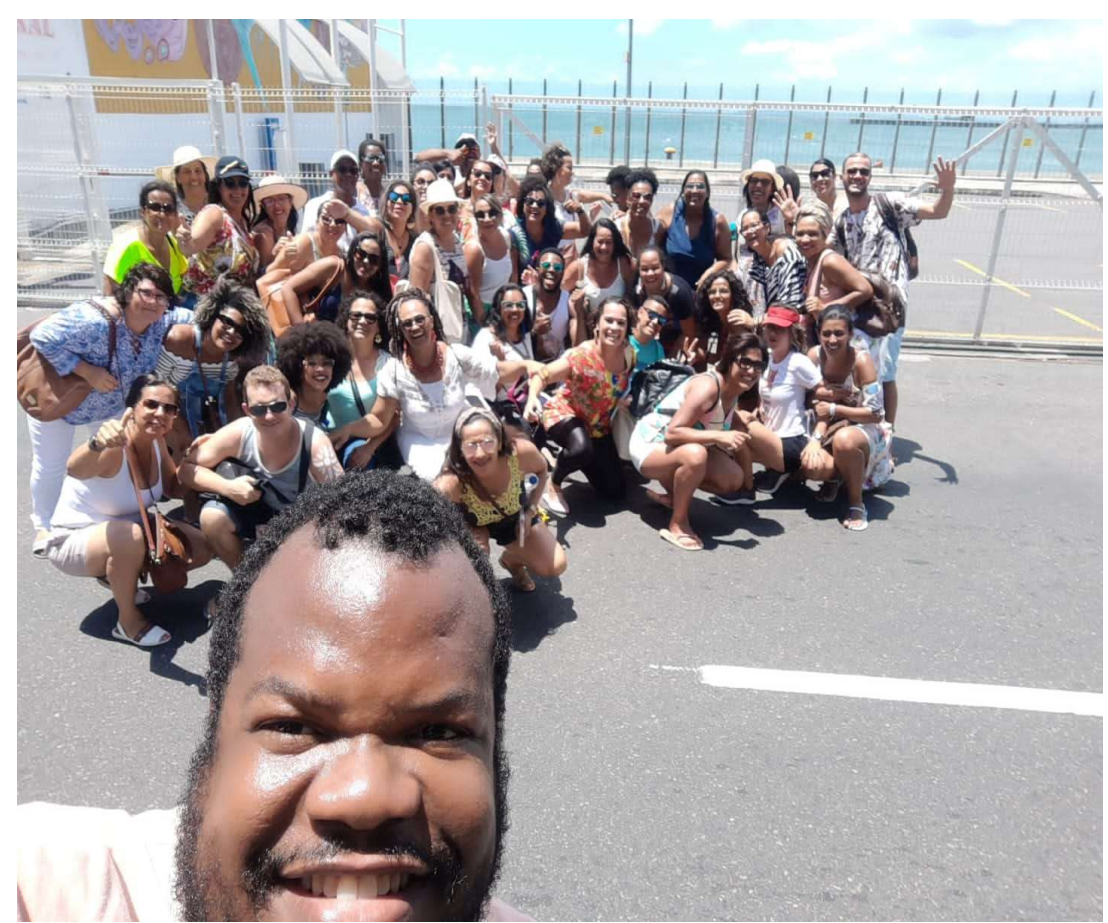

Figura 7: Foto dos cursistas de extensão do ODEERE durante a procissão de Santa Bárbara (Salvador, 2019). Fonte: Arquivo pessoal do autor.

Outro local de imenso valor pessoal foi a ida ao Quilombo de Quingoma, como ativista racial, estar nesses espaços acrescem diretamente na nossa formação e reflexão do nosso papel cidadão e como ativista. Assim, fortificando o interesse pela luta e entender a necessidade de estar sempre aberto a aprender, principalmente pelos mais velhos. O quilombo de Quingoma foi constituído desde 1569 e é um dos primeiros quilombos formados no Brasil. O território passa por diversas dificuldades, inclusive pelo rio que foi "privatizado" aos ribeirinhos pelos imigrantes. Além disso, ainda há muitos percalços civis dado a violência dos milicianos tentando colocar medo na comunidade e expulsá-los dali, já que é um território rico por diversos outros fatores. 


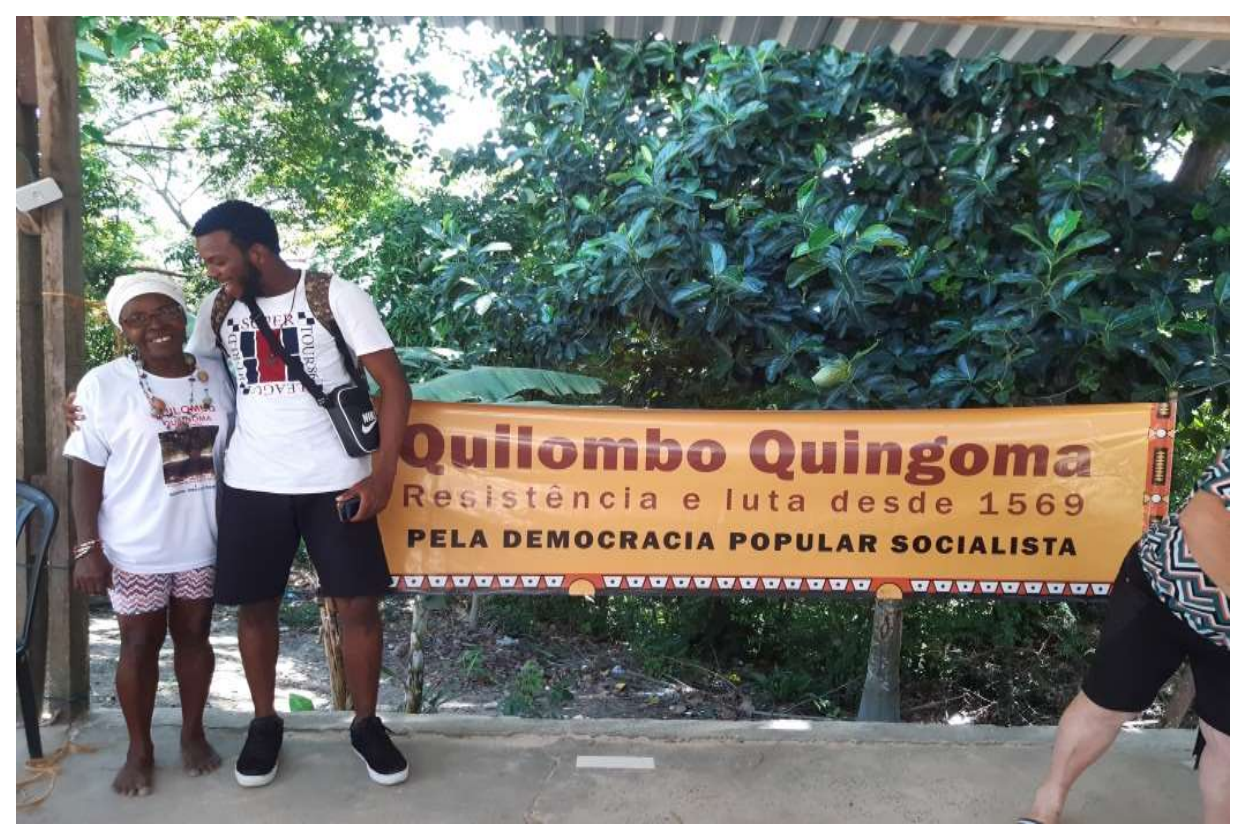

Figura 8: Foto do autor com uma das representantes do Quilombo de Quingoma (Lauro de Freitas, 2019). Fonte: Arquivo pessoal do autor.

Um momento gratificante durante a viagem foi poder estar na escola de Candeias. Poder ouvir jovens imigrantes, universitários da UNILAB, foi de grande valia. Compreender outros fatores acerca dos estudos dos nossos irmãos aqui no Brasil, além de contemplar espelhos sociais negros na condição de diretores, de coordenadores pedagógicos, até as demais funções da escola. Mais que isso, foi poder perceber a sensação de família tida ali, onde cada um dá o seu melhor pelo espaço e se compromete em favorecer a discussão racial dentro da escola. Os jovens do "Sarau da onça" também somaram concomitantemente ao evento, trazendo reflexões mediante as poesias.

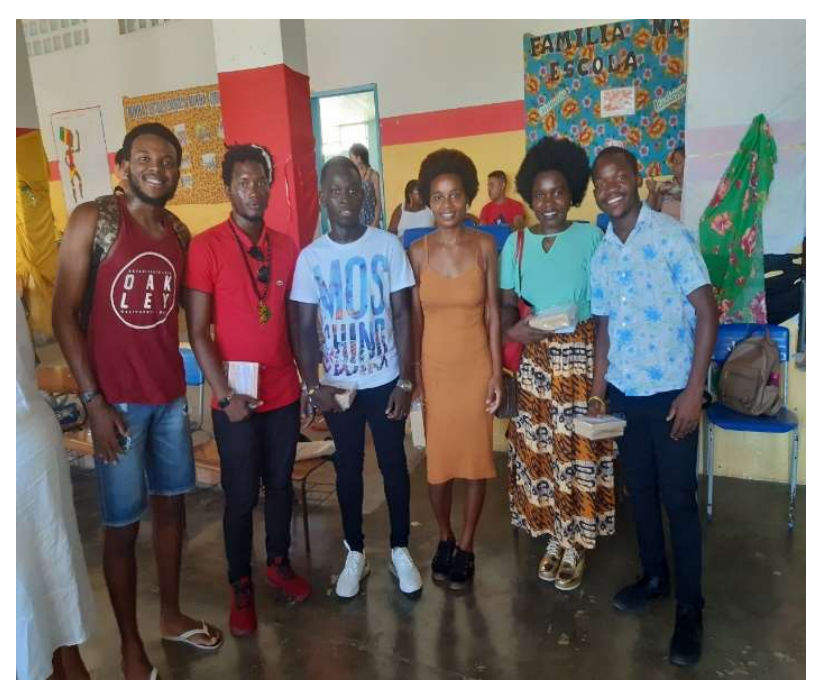

Figura 9: Foto do autor com com alunos da UNILAB. Candeias-BA, 2019). Fonte: Arquivo pessoal do autor. 
A visita ao museu afro se deu de forma emocionante, poder relembrar a partir de objetos da própria cultura, vendo a importância daquilo, a história, produziu maior identificação à cultura afro, isto é, reconhecer minha cultura como rica, como afrofuturista, inteligente e poderosa. Por fim, a viagem conteve diversos outros acontecimentos que corroboraram no aprendizado e deixou um sentimento de pertença, de respeito e de amor.

\section{CONSIDERAÇÕES FINAIS}

Durante esses 10 meses de estudos conhecemos pessoas maravilhosas que nos ensinaram de forma educada e compromissada saberes africanos e corroboraram na desconstrução de paradigmas acerca do nosso legado.

Assim, deixando não só o sentimento de gratidão pelo curso e das experiências ali vividas, mas também das pessoas e do espaço que carrega uma enorme energia positiva. Além disso, deixando a pretensão de fazer outro curso de extensão em 2020 e despertando mais interesse pelo legado africano. Ademais, intensificou nossos interesses pela especialização e mestrado contidos na instituição.

O ODEERE é uma família e nele se pode aprender valores e (des)construir saberes, ou melhor, resquícios da colonização que não nos contemplam mais por diversos fatores. Pela instituição somos reeducados e, principalmente, ela favorece que contemos nossa vida, nossas experiências para, a partir disso, interver no que preciso e corroborar nesse processo de ensino-aprendizagem aos mais novos. Cada professor, em seus respectivos módulos, demonstrou muito domínio e emprenho com as aulas, esse fato favorecia o nosso compromisso com o curso. Esses são os pontos positivos e importantes notados no decorrer dessa experiência.

Ao ingressar à comunidade do ODEERE pude ter o prazer de participar de um dos eventos de cunho étnico racial, evento ocorrido em Salvador-BA, o Fórum de pesquisadores negros da Bahia. Nele pude estar mais perto dos professores, pude apresentar dois trabalhos, publicá-los e estreitar os laços com os pesquisadores em comum. Isto posto, além de nos receber, o curso, os professores, a instituição também auxiliam no desenvolvimento e incentivo à pesquisa. 


\section{REFERÊNCIA BIBLIOGRÁFICA}

SANTANA, Marise de, ODEERE: formação docente, linguagens visuais e legado africano no sudoeste baiano / Marise Santana... [et al.]. - Vitória da Conquista: Edições UESB, 2014.

Sávio Oliveira da Silva Santos: Ativista racial e acadêmico do curso de Licenciatura em Letras com habilitação em Língua Portuguesa e Literaturas pela Universidade do Estado da Bahia, DCHT CAMPUS XXI. Representante discente do Colegiado de Letras Vernáculas. Desenvolveu pesquisa como Bolsista da Pró-Reitoria de Ações Afirmativas PROAF de 2017 a 2019 pesquisando sobre Negritude, Negrice e Negritice. Focaliza seus estudos no campo dos Estudos Culturais com as noções de Raça; Hip-Hop; Movimento Negro e Identidade.

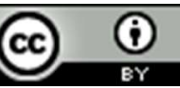
This work is licensed under a Creative Commons Attribution 4.0 International License.

(c) (i) Este trabalho está licenciado com uma Licença Creative Commons - Atribuição 4.0

Internacional.

Artigo recebido para publicação em: 18 de março de 2020.

Artigo aprovado para publicação em: 27 de abril de 2020. 